\title{
Staff views about the quality of the communicable diseases surveillance system in Khartoum state, Sudan, 2005-2007: a qualitative study
}

N. Sahal, ${ }^{1}$ R. Reintjes, ${ }^{2}$ A.E. Mahgoub ${ }^{3}$ and A.R. Aro ${ }^{7}$

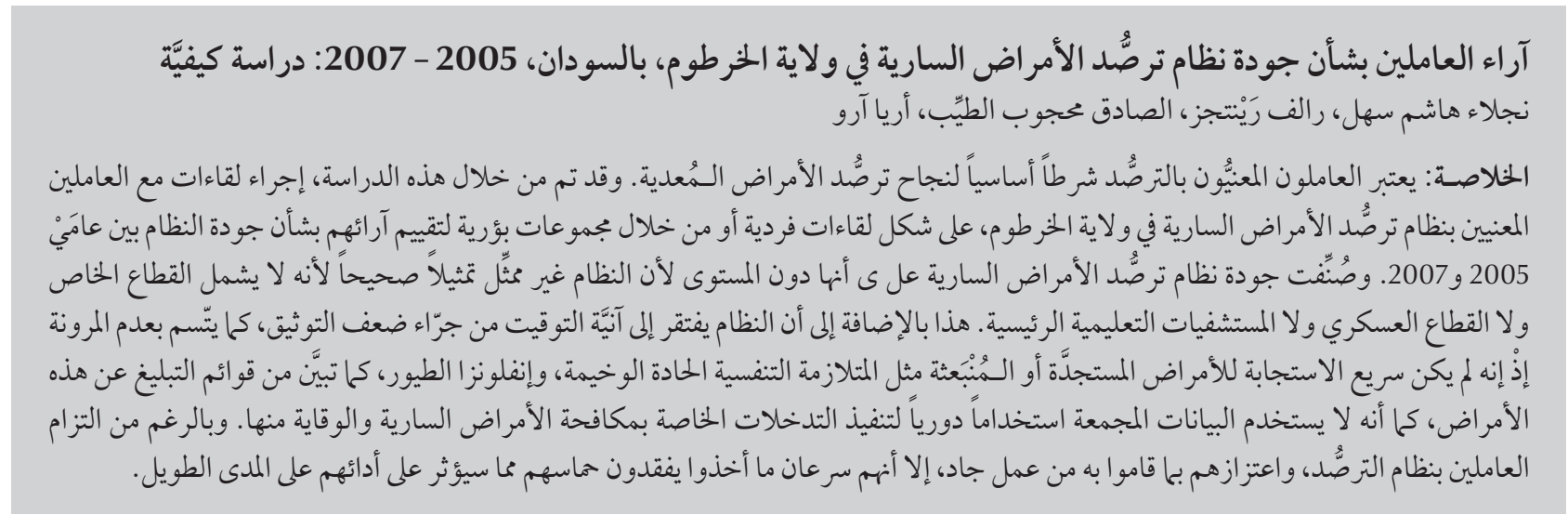

ABSTRACT Surveillance staff are vital to the success of surveillance of infectious diseases. In this study, we interviewed staff of the Communicable Diseases Surveillance System (CDSS) in Khartoum state individually and in focus groups to assess their views about the quality of the system for the years 2005-07. The quality of CDSS was considered poor because the system was not representative as it included neither the private nor military sectors nor the important teaching hospitals. It also lacked timeliness due to poor documentation, was inflexible since it did not rapidly respond to emerging and re-emerging diseases such as SARS and avian flu in its notification lists, and it did not use the data collected to apply interventions for control and prevention of communicable diseases on a routine basis. While staff were committed to the surveillance system and felt they worked hard, they were also demotivated and in the long run this might affect their performance.

Opinion du personnel sur la qualité du système de surveillance des maladies transmissibles dans l'État de Khartoum (Soudan) de 2005 à 2007 : étude qualitative

RÉSUMÉ Le personnel de surveillance est essentiel à l'efficacité de la surveillance des maladies infectieuses. Au cours de la présente étude, nous avons interrogé le personnel du système de surveillance des maladies transmissibles dans l'État de Khartoum, soit en groupe, soit individuellement, pour évaluer leur opinion sur la qualité du système entre 2005 et 2007. Le système de surveillance des maladies transmissibles était considéré comme étant de qualité médiocre, car il n'était pas représentatif. En effet, il ne couvrait ni le secteur privé, ni le secteur militaire, ni les hôpitaux universitaires importants. Le système manquait également de ponctualité en raison d'une mauvaise documentation. II n'avait pas non plus la souplesse requise, car il ne pouvait répondre rapidement aux cas de maladies émergentes ou réémergentes, tels le syndrome respiratoire aigu sévère et la grippe aviaire, dans les listes de notification. En outre, les données collectées dans le système n'étaient pas exploitées de manière systématique pour mettre en œuvre des interventions de lutte contre les maladies transmissibles. Même si le personnel était dévoué au système de surveillance et avait le sentiment de travailler dur, une certaine démotivation se faisait sentir et pourrait au long cours influer sur la performance.

'Unit for Health Promotion Research, Institute of Public Health, University of Southern Denmark (SDU), Esbjerg, Denmark (Correspondence to N. Sahal:nhsahal@health.sdu.dk).

${ }^{2}$ Department of Public Health, Faculty of Life Sciences, Hamburg University of Applied Sciences, Hamburg, Germany. ${ }^{3}$ Acute Flaccid Paralysis Surveillance Programme, Federal Ministry of Health, Khartoum, Sudan.

Received: 30/09/09; accepted: 19/01/10 


\section{Introduction}

Surveillance of infectious diseases is fundamental to public health decisionmaking and practice [1]. Surveillance data are crucial for monitoring the health status of populations, detecting diseases and triggering action to prevent further illness, and containing public health problems [1]. Most traditional global disease surveillance programmes target specific diseases; infrastructure and support is relatively weak for the more difficult task of tracking emerging and re-emerging diseases. This is particularly true in developing countries, where scarce human and material resources may not support even routine surveillance tasks [2]. In Sudan, the Communicable Disease Surveillance System (CDSS) in Khartoum State is part of the National Surveillance System launched in 1994. The system depends on a passive surveillance system for communicable diseases, which moves into active surveillance during epidemics or outbreaks [3]. In a descriptive, retrospective cross-sectional study, we assessed the core activities and support functions of CDSS in Khartoum state for the period 2005 to 2007 [4]. We found that the system was centralized, had not been updated, was poorly documented and had a shortage of staff at lower levels [4].

Staff play a central role in delivering quality service in health care [5]. This is as much in curative treatment as in disease surveillance. In infectious disease surveillance delay, negligence, lack of resources, and knowledge, attitudes and practices of the staff can lead to a rapid negative spiral, thus increasing risk to the population health. In addition to quantitative quality criteria, qualitative data might offer valuable contextual information and explanations for quantitative data. It is therefore surprising how few studies have been conducted on the views of staff on the facilitators and barriers to delivering disease surveillance.
To complete the picture of the Khartoum state CDSS quantitative assessment, we conducted a qualitative assessment of the quality of the system seeking the views of CDSS staff about the running of the system.

\section{Methods}

Personal and group interviews were conducted to gather views about activities related to the CDSS that had occurred during the 3 years of the study (2005 to 2007). A group interview format was used to assess CDSS activities as a whole. Participants in the personal interviews were representatives of both urban and rural localities ( $n$ staff members $=3$ ); health areas (management level above health facility) $(n=3)$; and health facilities $(n=3)$; as well as the State level $(n=4)$. Participants were selected randomly and all agreed to participate. Three focus group discussions were conducted, each including 8-10 CDSS staff members. Each focus group discussion lasted approximately 3 hours with a 15-minute break in between. The first author together with a trained health officer moderated the discussion in Arabic using an interview guide to gather views and experiences about CDSS activities.

The participation rate in the 3 focus group discussions was $100 \%$. The qualitative focus group data were analysed using content analysis based on themes arising from the data. After each focus group discussion the recorded tapes were transcribed, discussion notes were summarized and coded according to the relevance to different issues of the discussion. Quotations as examples of the participants' input were translated into English.

No numerical analysis was carried out. Significance in qualitative research, and particularly in a focus group, cannot be determined by the frequency with which a view or opinion is raised, but rather in the manner in which it is raised, discussed and negotiated by the group $[6,7]$.

\section{Results}

\section{CDSS completeness}

The staff expressed that for them it was difficult to assess the completeness of the CDSS data at health facilities. The following quote by a health officer from the health area level shows why: I was not able to tell if the data I received every week were all data that were registered in the health facility as I have no access to the raw data (Health officer, health area). However, checking the completeness of the data was possible during supervision visits: I can check the completeness of one or two diseases in the monthly supervision visit (Health officer, health area). Another reason given was that the surveillance data from private health care services or large hospitals were not included: We have a very large number of patients using the private sector but their data were not taken into consideration in our system (Health team head). The CDSS data from the important largest hospitals in the state were not included (Health officer, health area) and Data from Khartoum and Khartoum North teaching hospitals were not included after introduction of paperless hospital policy in those hospitals (Preventive medicine coordinator at the locality level).

\section{CDSS timeliness of reporting}

According to the staff, timeliness functioned well during epidemics: If we have an epidemic the system works well, for example when we had a haemorrhagic fever outbreak the daily active surveillance was able to identify all the cases in the recommended time (Health officer, locality level).

During non-epidemic periods there were problems especially on the lower levels of the surveillance system: The weekly report (we received) usually on Saturdays but without any kind of documentation of the time of occurrence (Health 
officer, health area) and Our health facilities (are) used to notify us but we are not able to find out if that is within the recommended time or not, and we are not able to know if these were all the cases or not (Health officer, health area).

\section{Usefulness of the surveillance data and the surveillance system}

The Khartoum CDSS seems to collect some data but is passive in using the information, e.g. in performing interventions. A focus group of preventive medicine coordinators remarked: We collect data for many communicable diseases (CD) but we do not carry out any interventions or prevention measures on a routine basis.

Neither are the data used for decision-making about resource allocation, which was expressed by a health officer at the locality level: We keep collecting CDSS data but all the resources have been fixed (unaltered) during the past years. In addition, the CDSS guidelines or case definitions have not been updated for years according to the interviewees at the locality level. Although the CDSS in Sudan has worked well in detecting some epidemics and it has done it in the recommended time, it seems that this tends to happen when the epidemic starts from a chosen sentinel site for CDSS. However if is occurs elsewhere the system may not be as efficient, as mentioned by a participant at the state level: If the outbreak started from a private sector we may not discover it or we can do that very late

Moreover, there is a serious problem in the notification lists as mentioned by a surveillance coordinator at the central level: Our notification lists contain some diseases in form of symptoms or signs, which can be related to both communicable and noncommunicable diseases such as watery diarrhoea, bloody diarrhoea and jaundice.

\section{Simplicity of the system}

The structure of CDSS in Khartoum is quite simple. Traditionally, the data reporting procedures have been based in Microsoft Excel. According to some interviewees, it takes only an hour to finish a weekly report, and mostly only simple manual graphs are drawn.

\section{Representativeness of the surveillance system}

The CDSS in Khartoum is based on 150 sentinel sites that chosen using standard criteria such as geographical position and patient load. One of the interviewees (Health officer, locality level) said: The (CDSS) system started with 76 (facilities) in 1998, which were chosen based on certain criteria and then every year 'they' added 25 health facilities until 'they' reached 150 in the year 2003. Then (the increase) stopped and no one knows why they won't (continue to) add 25 health facilities every year.

As mentioned earlier in the Completeness paragraph, the representativeness of CDSS suffers from the lack of inclusion of private sector data: Although very large portion of the population were treated in private hospitals and clinics we did not collect data from these facilities (Health officer, locality level). Similarly, military hospitals were not included in the CDSS. Representativeness is also affected since according to an interviewee: There are no diagnostic standard guidelines (Health officer, locality level).

\section{Flexibility}

One of the main weaknesses of the CDSS in Khartoum is its inability to implement changes rapidly: We feel that the list of notifiable diseases needs to be changed but nothing happens (Health officer, locality level). In line with this, old case definitions seem to persist: Even if even doctors dislike using them (Health officer, locality level).

\section{Acceptability}

Despite the fact that the CDSS in Khartoum state lacks legislation for compulsory CDSS reporting, the system has a high level of acceptability as mentioned by most of the respondents: Notification of $C D$ is an important issue (which) we keep doing (Health officer, State level). On the other hand, almost all the respondents thought that Khartoum CDSS lacks enough motivational factors for the staff: We have done a perfect job for the system for years and we feel that emotional and monetary motivation were declining with years and now seems to be absent completely (Health officer, State level).

\section{Sensitivity}

Sensitivity is an important parameter measuring the quality of the CDSS system as it determines the true fraction of cases that are notified to CDSS. Unfortunately, Khartoum state has no other parallel system for communicable diseases data and even the laboratory data documentation is considered to be a very poor system for information on communicable disease cases, as mentioned by a surveillance officer from the central level: Our laboratory data documentation of communicable diseases is very poor and no other system collects similar communicable diseases data so we do not know if the cases we have are all what we must have or not.

\section{Discussion}

These personal interviews and this focus group-based qualitative study give explanations and examples, which help to understand the value of the Khartoum CDSS as well as facilitators and barriers to delivering high quality surveillance. Our interviewees added useful information to our previous e paper on the CDSS criteria met by the Khartoum CDSS [4]. Moreover, it is important to take staff views into account as listening to their opinions enhances their ownership, acknowledges their important role in operating the system and gives them motivation for better performance within the system. The most important findings are discussed below. 
The completeness of data from CDSS in Khartoum is a real problem, as there was no method for continuous checking the completeness of the data received from the health facilities. Furthermore, the data from both private and military sectors, where a large portion of population is treated, were not included in CDSS data and neither were data from 2 large teaching hospitals in the state. Incompleteness of CDSS in Khartoum decreases the value of the system and gives misleading estimations of the magnitude of then communicable diseases burden. The situation of Khartoum CDSS data incompleteness is similar to other states in Sudan [8], the situation with the measles control in the Unites States of America in 2004 [9], that of Legionnaires diseases in France in 2003 [10] and tuberculosis control in Netherlands [11], to name just a few examples.

Another problematic issue hindering the usefulness of the CDSS was that the system remained passive except during epidemics when surveillance was activated and daily notification was mandated.

Timeliness of the system was a further problem and this was likely to be due to the primitive non-electronic method of reporting. The impact of electronic reporting on timeliness has been documented in Sweden [12] and Hawaii [13].

A public health surveillance system is useful if it contributes to the prevention and control of adverse healthrelated events [14]. Unfortunately, the CDSS in Khartoum in its current form is of limited use as no prevention and control measures were applied to the cases reported by the system and interventions were only initiated during outbreaks. Moreover, the disease list contained symptoms, which could also be symptoms of noncommunicable diseases, such as watery diarrhoea, bloody diarrhoea and jaundice. This may lead to over-notification because these data are compiled as a state report at the federal level for diseases such as dysentery and viral hepatitis.

Surveillance systems should be as simple as possible in their structure and easy to operate while at the same time meeting their objectives [14]. However, the Khartoum CDSS is perhaps too simple in its structure and operation at all levels with its uncomplicated data reporting and analysis system. This is true also in all other Sudan states [8] and in Australia [15].

Surveillance systems need also to be flexible A flexible public health surveillance system can adapt to changing information needs or operating conditions with little additional time, personnel or allocated funds [16]. However, the Khartoum CDSS is an inflexible system due to the failure to adopt changes for emerging diseases such as SARS and avian flu in its notification list.

The CDSS of Khartoum state is a sentinel surveillance system [16], and can provide simple, early detection of diseases [17]. However, a problem of such a system is that the data may not be representative of the entire population at risk [18] nor sufficient to calculate statistically significant rates and ratios, which are important for assessing changes in the population health status [18]. In addition, absence of data from the private and military sectors means that the CDSS in Khartoum is not a representative system. In such a situation, the data collected will not be beneficial for allocation of resources and decision-making, which means that the system is not fulfilling its objectives and the reason for its existence is undermined.

Unfortunately, there was no other system in place to be able to assess the sensitivity and specificity of the CDSS in Khartoum. However, since the system does not cover all health facilities, it can be assumed that it is neither sensitive nor specific. The situation is the same in all other Sudanese states as well [8] but highly sensitive systems are achievable, as in Sweden [19].
The major strength of Khartoum CDSS lies in its universal acceptability by the staff and its acceptance as a primary source of communicable disease data in the State. The Khartoum CDSS staff are committed to participation in the system, but they also suffer from poor emotional and monetary motivation despite their hard work within the system; in the long run this might affect their performance and commitment to the system.

This study used focus group discussion; the participants were chosen to represent the different level of CDSS in order to overcome selection biases. Tangential or irrelevant discussions were easily controlled as the researcher was the moderator. However, respondents could have felt peer pressure to give similar answers and this might have affected the data obtained from the discussion. The focus group discussions were in Arabic and then translated into English, which might also have affected the data quality. In addition, some of the studies we used to compare our result with were not based on staff views but on other qualitative and quantitative methods.

\section{Conclusion}

This qualitative study complements our quantitative work [4] by exploring areas not amenable to quantitative study. The results provided useful information about the CDSS in Khartoum from the point of view of the staff at the different levels of the system. The staff considered the quality of CDSS poor because the system was not representative, it was incomplete, it lacked timeliness, it was inflexible, and it had poor incentives for the staff.

It is clear that the Khartoum CDSS needs to implement interventions to improve the quality of the system. The staff made the following recommendations: expansion and revision of the existing sentinel surveillance system to 
include private and military sectors; introduction of an electronic reporting system either by fax or Internet at all levels of CDSS; updating of the communicable diseases case definitions; modification and updating of the communicable diseases notification list; application of intervention measures for communicable diseases; and strengthening of the laboratory data documentation system. Unless rapid, extensive and robust interventions are carried out to improve its quality, the Khartoum CDSS will not achieve its targeted goals.

\section{References}

1. Communicable disease surveillance and response systems. A guide to planning. Geneva, World Health Organization, 2006 (http://www.who.int/csr/resources/publications/surveillance/WHO_CDS_EPR_LYO_2006_1.pdf, accessed 24 May 2011).

2. Choffnes E. Improving infectious disease surveillance. Bulletin of atomic scientists, 2008. (http://www.thebulletin.org/webedition/op-eds/improving-infectious-disease-surveillance, accessed 24 May 2011).

3. A report of the strategic plan for national communicable disease surveillance in Sudan. Khartoum, Sudan, Khartoum State Ministry of Health, Epidemiology Department, 1996.

4. Sahal $\mathrm{N}$ et al. Assessment of core activities and supportive functions of the communicable diseases surveillance system in Khartoum state, Sudan for the years 2005-2007. Eastern Mediterranean Health Journal, 2010, 16:1204-1210.

5. Atherton F, Mbekem G, Nyalusi I. Improving service quality: experience from the Tanzania Family Health Project. International Journal for Quality in Health Care, 1999, 11:353-356.

6. Focus Groups. In: Richie J, Lewis J, eds. Qualitative research practice: a guide for social science students and researchers. London, Sage, 2005.

7. Bowling A. Research methods in health: investigating health and health services, 2nd ed. Oxford, Oxford University Press, 2004.

8. Mahdi TF. An interventional study to: strengthen the national communicable disease surveillance and response systems in Sudan. Khartoum, Sudan, Khartoum State Ministry of Health, 2003 (Research document).

9. Harpaz R. Completeness of Measles Case Reporting: Review of Estimates for the United States. Journal of Infectious Diseases, 2004, 189(Suppl. 1):S185-190.

10. Nardone A et al. Repeat capture-recapture studies as part of the evaluation of the surveillance of Legionnaires' disease in France. Epidemiology and Infection, 2003, 131:647-654.
11. Van Hest $\mathrm{H}$ et al. Completeness of notification of tuberculosis in The Netherlands: how reliable is record-linkage and capture recapture analysis. Epidemiology, 2006, 7:1-9.

12. Jansson A et al. Timeliness of case reporting in the Swedish statutory surveillance of communicable diseases 1998-2002. Scandinavian Journal of Infectious Diseases, 2004, 36:865-872.

13. Effler $\mathrm{P}$ et al. Statewide system of electronic notifiable disease reporting from clinical laboratories: comparing automated reporting with conventional methods. Journal of the American Medical Association, 1999, 282:1845-1850.

14. Updated guidelines for evaluating public health surveillance systems Recommendations from the Guidelines Working Group. Morbidity and Mortality Weekly Report Recommendations and Reports, 2001, 50(RR-13):1-35 (http://www.cdc.gov/ $\mathrm{mmwr} /$ preview/mmwrhtml/rr5013al.htm, accessed 23 May 2011).

15. Miller M et al. Evaluation of Australia's National Notifiable Disease Surveillance System. Communicable Diseases Intelligence, 2004; 28:311-323.

16. Jernigan DB et al. Sentinel surveillance as an alternative approach for monitoring antibiotic-resistant invasive pneumococcal disease in Washington State. American Journal of Public Health, 2001, 91:142-145.

17. Cameron S. Public Health surveillance for communicable diseases in South Australia. Public Health Bulletin of South Australia, 2006, 4:2-5 (http://www.health.sa.gov.au/pehs/ publications/PHB-comm-disease-ed4-06v2.pdf, accessed 23 May 2011).

18. Disadvantages of sentential communicable disease surveillance system. Khartoum, Sudan, Department of Epidemiology, Khartoum State Ministry of Health, 2001.

19. Jansson A, Arneborn M, Ekdahl K. Sensitivity of the Swedish statutory surveillance system for communicable diseases 1998-2002, assessed by the capture-recapture method. Epidemiology and Infection, 2005, 133:401-407. 